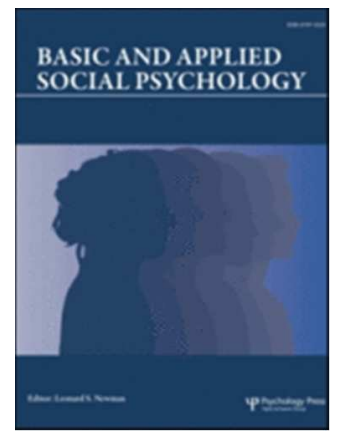

\title{
Can Empathy Promote Cooperation when Status and Money
} Matter?

\begin{tabular}{|r|l|}
\hline Journal: & Basic and Applied Social Psychology \\
\hline Manuscript ID & HBAS-2017-0088.R4 \\
\hline Manuscript Type: & Original Article \\
\hline Keywords: & cooperation, status, chance vs. effort, empathy, public goods game \\
\hline \multicolumn{2}{|c}{} \\
\hline
\end{tabular}

SCHOLARONE $^{\text {m }}$

Manuscripts 


\title{
Can Empathy Promote Cooperation when Status and Money Matter?
}

\begin{abstract}
In the present study, we ask: Does empathy also support cooperative behaviors when the status (high, low) of an individual differs relative to other group members and is determined by either chance or effort? In response to this unexplored question, the present study involved a series of four experiments using a linear public goods game (Experiment 1-3, 4-player, Experiment 4, 2-player). Regardless of the way in which status was achieved (chance, effort) those with low status cooperated more compared with their high status counterparts. Empathy in and of itself revealed very small overall increases in cooperative behavior. Overall, status and monetary incentives appear to be more salient than empathy in guiding behaviors in a social dilemma task.
\end{abstract}

Keywords: status, cooperation, chance vs. effort, empathy, incentives, public goods game (PGG), 


\section{Introduction}

How we come to gain our resources has been a matter of interest for many psychologists and economists, because the general speculation is that we are uniquely tuned to whether they are gained fairly or unfairly. For instance, equality of opportunity (Loury, 1981) refers to situations in which, ceteris paribus (all else being equal), the opportunity for gaining resources is either determined through chance factors, which all members of a group are subject to, or through effort alone. This means that the perception of fairness in the opportunities to gain resources will vary with respect to how they are gained, and there is speculation that this also influences the type of interactions between individuals of differing levels of resources. For instance, the psychological state of fairness is "the concern to be treated equally, includes the concern for how much money or resource are distributed amongst individuals (distributive fairness) and the belief that one should receive what one is due based on one's actions (reciprocal fairness)" (Kamas \& Preston, 2012, p. 538). Moreover, Yamamoto and Takimoto (2012) claim that prosocial behaviors, motivated by empathic concerns, can only exist in connection to a sense of fairness, which is determined by the way in which resources are gained and how they are distributed. The implications here being that, empathic concern may support pro-social behaviors within a social context, but these may be potentially attenuated depending on how unfairly resources are perceived to be, or actually, gained.

On this basis, the present study aims to address the following two questions: 1) To what extent are pro-social behaviors impacted in situations in which the resources gained (either through chance or effort) by one individual in the group differ? 2) To what extent does empathy promote pro-social behaviors given the way in which one individual in a group achieves their status (i.e. through chance or effort)? Thus far, prior work has examined these questions separately, and so the aim of the present study is to address both within the same experimental set up. To investigate the first question, in a pro-social decision-making task, 
the impact on pro-social behaviors was examined when the status achieved by one individual within the group, was determined experimentally by the amount of initial endowment (High vs. Low), achieved either through effort or chance. To investigate the second question, given the manipulation of status, empathy was experimentally induced towards other individuals in a group decision-making task in order to investigate the impact on pro-social behaviors. In what follows, we first provide details regarding the operationalization of the key concepts (i.e. cooperation, status, empathy) that inform the manipulations we introduce in our experiments, we then discuss previous work examining the relationship between status and cooperation, and empathy and cooperation, and thereafter provide the theoretical foundations for the specific predictions we test in our four experiments.

\section{Operationalization of Cooperation, Status, and Empathy}

Cooperation: Pro-social behaviors are often taken to include a broad category of acts that are agreed by some significant proportion of society, or one's social group, as behaviors that are generally beneficial to others (Penner, Dovidio, Piliavin, \& Schroeder, 2005). In the present study, consistent with others (Marcus, 1991), we treat cooperation as an example of a pro-social behavior. In definitions of cooperation, an essential property is the relationships between the individual's roles within a group. If cooperation is considered from the perspective of an individual within a group, the definition of cooperation is behavior that benefits the group or collective, often at the cost of individual benefits (Irwin, McGrimmon, \& Simpson, 2008). If cooperation is considered from the view of individuals performing joint behaviors, then cooperation is behaviors directed toward a goal in which the participants gain equal rewards (Marwell \& Schmitt, 1975), and, to further qualify the mutual aspect, they should also have shared intentions (Derlega \& Grzelak, 1982; Liebal, Colombi, Rogers, Warneken, \& Tomasello, 2008; Warneken \& Tomasello, 2007). However, as many have discussed, outcomes of cooperative behaviors need not be based on altruistic motivations, 
and so in the same vein, joint action need not be based on mutual motivations. Crucially the shared goal of the cooperative endeavor is key. Thus, consolidating the different approaches to conceptualizing cooperation, we propose that what is critical to cooperation is behaviors directed toward a shared goal in which a participant performs an action that another(s) gain rewards from.

Status: When it comes to status, in the present study we treat status as a term that includes, but is not limited to, constructs such as socioeconomic status (SES), social influence resource-holding potential, and social class (Kafashan, Sparks, Griskevicius, \& Barclay, 2014), the latter of which has been found to affect behaviors associated with social engagement (Cote, 2011; Kraus \& Stephens, 2012). Status here tends to reflect subjective judgments about one's standing within a group (relative to others in that group), and is often based on one's views about one's prestige, for which "respect" gained by others is the basis of judged prestige as proposed by the group engagement model (Tyler \& Blader, 2003). Alternatively, and a concept adopted in the present study, is that status is determined more explicitly by the assets that each member of the group have gained (i.e. financial wealth relative to each group) (Bothner, Kim \& Smith, 2012).

Empathy: Empathy has been defined as "the ability to recognize and understand the thought process of another" (Underwood \& Moore, 1982, p. 144) and "the ability to identify and understand the feelings of another" (Krebs, 1975, p. 1135). Here empathy consists of two components, cognitive empathy and affective empathy. Cognitive empathy is also called "cold" empathy or "perspective taking" or "theory of mind", whereas affective empathy is referred to as "hot" empathy (Loewenstein, 2000; Paal \& Bereczkei, 2007). Empathy, in general, makes it possible to understand the behaviors of family, friends or even strangers, from the point of view of the emotional reasons behind their actions. Some have gone as far to suggest that without empathy, it is impossible for us to interact with others appropriately 
(Baron-Cohen, 2011). Given the multifaceted nature of empathy, some researchers have attempted to consolidate the various aspect of empathy by considering eight uses of the term of empathy (Batson, 2011, pp. 12-19). Looking across the various definitions of empathy, and consolidating much of the social psychological literature on empathy, we propose that typically empathy is an other-oriented emotion elicited by and congruent with the perceived welfare of someone in need. The emotional states that are elicited can include sympathy, compassion, softheartedness, tenderness, sorrow, sadness, upset, distress, concern, and grief; and it involves feelings for the other rather than the self. Put more succinctly, our definition treats empathy as an emotional state in which people display "empathic concern", though this could also be dispositional, in that people vary in the degree to which they display the state of empathic concern.

\section{Previous work examining associations between achieved status and cooperation}

Previous work has explored the basis on which status is achieved and the impact that it has on pro-social behaviors. Several studies have manipulated the basis on which assets are gained (i.e. tokens that were then used in a cooperative game) either through chance, or through effort. For instance, in some cases participants were randomly assigned to one of two conditions in which effort (high vs. low) determined the basis on which assets (50 tokens) were gained (Muehlbacher \& Kirchler, 2009). Alternatively, tokens could be randomly assigned to participants by the experimenter in advance to mimic acquisition of assets via inheritance (Komorita, Parks, \& Hulbert, 1992) or via lotteries. Equal opportunity via effort was examined by assigning tokens based on performance on a specific task prior to playing a cooperative game, which was designed to mimic situations in which access to greater wealth is achieved by meeting performance criteria in job settings (Kroll, Cherry, \& Shogren, 2007). Taken together, the general pattern of findings suggests that cooperative behaviors are reduced for those that achieve their status through effort (Muehlbacher \& Kirchler, 2009; 
Rockmann \& Northcraft, 2008). However, thus far, there is no direct comparison of the impact on cooperation, within the same task paradigm, when assets are achieved either through chance or effort. Moreover, there are no direct comparisons of achieved status (i.e. through chance or effort) on cooperative behaviors within a group, when status manipulations impact only one of the members of the group. Thus, prior work provides vital clues regarding a link between status and cooperative behaviors, but does no enable a clear understanding of the degree to which status gained by either chance or effort has differential effects on levels of cooperation within a group, which provides further motivation for our study.

\section{Previous work examining associations between empathy and cooperation}

One of the most common ways to promote cooperation is through the inducement of empathy. Typically, empathy inducement methods (e.g., the presentation of stories of suffering, or being instructed to perspective take) is introduced as an independent variable in experimental studies in order to examine the effects of empathy on cooperation in laboratory settings using variants of economic games (e.g. Public Goods Game (PGG), Prisoners Dilemma). Many studies have reported that empathy induction promotes or at least maintains cooperative behaviors (Allsop, Fifield, \& Seiter, 2002; Batson \& Moran, 1999; Cialdini et al., 1987; Eimontaite, Nicolle, Schindler, \& Goel, 2013; Fultz, Batson, Fortenbach, McCarthy, \& Varney, 1986; Oswald, 1996, 2002; Pavey, Greitemeyer, \& Sparks, 2012; Rumble, Van Lange, \& Parks, 2010; Stürmer, Snyder, Kropp, \& Siem, 2006; Xu, Kou,Zhong, 2012). However, investigations that have since tried to replicate these studies have reported a null effect of empathy induction on cooperation (LV, Proulx, Osman, 2015; Oswald, 1996; Warren \& Walker, 1991; Xu et al., 2012, Study 2). Other than typical cooperative laboratory based tasks, alternatives such as resource allocation games that involve negotiation between groups of participants, have tried to induce perspective taking (i.e. cold empathy) (Epley, Caruso, \& Bazerman, 2006; Gilin, Maddux, Carpenter \& Galinsky, 2012) as well as empathy 
(i.e. hot empathy) (Cohen, 2010; Galinsky, Maddux, Gilin, \& White, 2008; Gilin, et al, 2012) as a means of promoting pro-social behaviors. As with studies using economic type games, the findings here are also mixed. Taken together, the pattern of findings regarding the positive impact of empathy, both hot and cold versions, on pro-social behaviors is not reliable, particularly perspective taking manipulations. For this reason, we aim to further investigate whether it might be the case that the empathy-cooperation link is more likely to be strengthened in situations where resources are gained fairly (equal-resource distribution) as compared to less fairly (unequal-resource distribution) (Yamamoto \& Takimoto, 2012).

\section{Theoretical underpinnings}

As outlined earlier, one motivation of the present study is to examine the link between the basis on which status is gained, and levels of cooperative behavior. Kafashan et al. (2014) has proposed that the association between the two arises as a result of two different functions, based on their bi-directional causation account for which there is considerable evidence. Either pro-social behavior can be used to help achieve status (Willer, 2009a), or possessing status can change the perceived costs and benefits of engaging in pro-social behavior; this second functional role is the focus of the present study. The former suggests that collective behaviors can be used to profit an individual's status, thus prosocial behavior functions to achieve or maintain status, which can either be material or social rewards. For instance, in a management context, group performance can contribute to the status of an individual that is taking responsibility for the group (i.e. the formation of leaders) (Henrich, Chudek, \& Boyd, 2015), the impact of which can be material as well as reputational.

With regards to the second functional association, the status of an individual can impact the dependency of others within a group, and they behave pro-socially to maintain or lessen the status of the individual within the group. For instance, there is considerable work showing that when it comes to charitable donations low-status individuals are more likely to 
show pro-social behavior than high status individuals (Bennett, 2012; Guinote, Cotzia, Sandhu, \& Siwa, 2015; Piff, Kraus, Côté, Cheng, \& Keltner, 2010). One reason for this is that inflated personal views of one's personal status can be used to justify the reduced levels of generosity towards other group members (Hays \& Blader, 2016); the costs are perceived as high and the benefits are perceived as low with respect to inequality of resource allocation. Resource-based exchange theories claim that the exchange of material resources is the fundamental reason that people act cooperatively, including interdependence theory (Joireman, Kuhlman, Van Lange, Doi, \& Shelley, 2003; Kelley \& Thibaut, 1978; Van Lange \& Gallucci, 2003). Alternatively, identity-based theories such as group engagement model (Tyler \& Blader, 2003) and appropriateness framework (Weber, Kopelman, \& Messick, 2004) claim that behaving cooperatively helps to obtain identity through group membership. According to resource-based exchange theories, differences in social status affects one's costs and benefits analysis with resultant changes in behavior towards others. Therefore, if changes occur to a person's relative status within a group, the proclivity for cooperative behavior will change due to either the change in obtained material resources, or the relative identity they could potentially obtain.

Some work has looked at the extent to which these theoretical accounts are supported empirically through laboratory tasks such as linear public goods game (PGG) which consists of only one Nash equilibrium that everyone contribute nothing, and one Pareto efficient solution that everyone contribute everything (Abele, Stasser, \& Chartier, 2010). Here each of four players can choose to contribute a certain amount of their endowment to a common pot (i.e. an index of cooperation), which is distributed equally amongst all four players. In typical versions of linear PGG each player is endowed with the same amount of tokens (homogenous set up), but introducing heterogeneity via an unequal amount of tokens can serve as a proxy for different levels of status (Cherry, Kroll, \& Shogren, 2005). Consistent with work on status 
and charitable donations, there is some evidence to suggest that low-status individuals (i.e. those endowed with less tokens than the rest of the group) contributed more than high status individuals (Bennett, 2012). Given that experimental manipulations of endowment heterogeneity in PGG creates a lab-analogue of low-status and high-status, we use a similar paradigm in the present study. Based on previous work assuming a functional relationship such that status affects the costs and benefits of pro-social behavior, high status individual will view the costs of pro-sociality as higher than low status individuals, because of their perceived entitlement of their status. Thus we test the following predictions:

Prediction 1: Overall low-status individuals will show greater cooperation, as evidenced through contributions to a public good, compared to high-status individuals.

Prediction 2: If perceived entitlement plays a role, then high status individuals will feel more entitled when they achieve their status through effort than when achieved through chance, and so will display lower levels of cooperation through contributions to a public good compared to high-status individuals achieving their status through chance.

To the extent that individuals show any cooperative behaviors in the empirical work discussed, we need to consider what the possible underlying mechanism is that promotes this type of behavior. Moreover, if high status individuals typically show less cooperative behaviors than low status individuals, we consider it of importance to empirically investigate ways in which we can artificially promote cooperative behaviors through empathy. The grounds on which we consider the potential positive impact of empathy on promoting cooperation in general, as well as on those that achieve high status, comes from social psychological research. Social psychological theories claim that humans display cooperative behaviors through a mechanism that suggests a central role for empathy.

Existing resource-based exchange theories emphasize self-interested motives or economic motivations as the basis on which cooperative behaviors are observed. Nonetheless, 
economic motivations (i.e. maximizing personal wealth) do not fully explain the range of possible reasons for acting cooperatively in mixed-motives dilemma games (e.g., PGG). For these reasons alternative accounts have been proposed that suggest empathic concern for others can motivate cooperative behaviors at a personal cost to each individual.

One reason for this is that it is claimed that a feature of humans that apparently sets us apart from other species is our focus on others' well-being (broadly referred to as altruism) (Batson, 2011). Also, we will, sometimes, at great personal cost, protest outcomes that we consider unfair, whether they personally affect us or have no direct impact on our lives. The association that empathy has with altruism in turn has implications for the basis on which empathy promotes cooperative behaviors; relevant theories associated with this are empathyaltruism hypothesis theory (Batson, 2011) and the negative-state relief hypothesis (Cialdini, Kenrick, \& Baumann, 1982). The former assumes that empathy will produce concern for another's welfare, which motivates the individual to act pro-socially. The later argues that empathy induction triggers egoistic motivations, in which individuals act pro-socially in order to relieve the negative affective state - one of temporary sadness or sorrow- by witnessing another person' suffering. Both theories predict that empathetic concern (either through perspective taking or affective empathy) promote cooperative behavior, but diverge significantly with respect to the underlying motivation (altruism or egoism). In the case of the empathy-altruism hypothesis (Batson, 2011), it predicts that if we feel empathetic concern for another group member, we will be altruistically motivated towards them, which is observed through contributing tokens to the group pot in a PGG. Given that neither of these theoretical accounts make any specific claims that could be used to generate predictions with respect to status, we consider the fairness and empathy account proposed by Yamamoto and Takimoto (2012). They claim that empathy promotes prosocial behaviors, whereas a sense of fairness stabilizes prosocial behaviors. The two work in tandem, where empathy promotes prosocial 
behaviors under a sense of fairness, and empathy is attenuated under conditions in which a sense of fairness is undermined. In fact, they claim that empathy alone will not operate in promoting prosocial behaviors in the absence of a sense of fairness. They also claim that the basis of the complementary role between the two is driven by an evolved preference for similarity to others. That is, the more similar we perceive we are to others, the more likely it is that, through a sense of fairness, empathy will promote prosocial behaviors. Thus, in the present study, given our empathy manipulations, we test the following predictions:

Prediction 3: Overall, when perspective taking inducements of empathy are present, irrespective of status manipulations, there should be greater displays of cooperation through contributions to a public good compared to no-empathy inducements.

Prediction 4: If a sense of fairness is used to complement empathy in supporting cooperative behaviors, then under conditions in which empathy inducements are present, there should be evidence of an impact of empathy on cooperation under conditions in which the status of individuals is equal (i.e. fair), rather than unequal (unfair).

\section{General Methods}

Overview

In the present study four experiments were reported in which real participants were exposed to a series of 10 rounds in a linear PGG while interacting with three fictional players (Experiments 1-3), and another real player (Experiment 4). The assignment of participants to key experimental conditions (high-status v.s low-status) in Experiment 1 was based on a random draw of a colored ball picked from an occluded black box (chance-status). Thus, Experiment 1 tested predictions 1, and 3. In Experiment 2 participants were assigned to status conditions (high-status vs. low-status) according to their performance on a digit cancellation test (effort-status), and thus tested predictions 1, 2, and 3. Experiment 3 was a pure test of the 
manipulation of empathy on cooperation, in which the endowments were the same for all participants. Experiment 3 tested prediction 3 and 4. Experiment 4 was a replication and extension of Experiment 1 in which all players in the 2-player PGG were real and interacted with each other, and in which the allocation of status (low-status, equal-status) was dependent on chance (chance-status). Experiment 4 tested prediction 3 and 4.

In all four experiments the analysis of the data was the same. We first checked the effectiveness of the empathy manipulation and then conducted a mixed repeated-measures ANOVA to examine the effects of empathy and status on cooperation using proportion of contribution $(\mathrm{PoC})$ in the PGG.

\section{Experiment 1}

Experiment 1 was designed to test the extent to which empathy (through perspective taking manipulations) induced cooperative behaviors in a PGG under conditions in which status (high-status, low-status) was achieved through chance.

Method

\section{Participants}

Ninety-four volunteers (58 female and 36 male) were recruited from Queen Mary University of London via emails and fliers. The mean age of the participants was 20.71 years (range from 18 to $32 ; S D=3.09$ ). Based on the condition they were assigned to, they were given different final payments. In the high-status condition, participants were paid between $£ 10$ and $£ 15$ (\$14.02 - \$21.02); in the low-status condition, participants were paid between $£ 5$ to $£ 7(\$ 7.01-\$ 9.81)$.

All participants gave written informed consent prior to participation. After the experiment, they were paid an amount for their participation on the basis of the tokens gained in the PGG. In each PGG 25 tokens was equal to $£ 1$ (\$1.40), which all participants were made aware of at the start of the experiment. The Ethics Committee of the university 
approved the study. The experiment was carried out in accordance with The Code of Ethics of the World Medical Association (Declaration of Helsinki); as with the other three experiments.

\section{Design and Materials}

Experiment 1 was a $2 \times 2$ (Empathy [high-empathy, no-empathy] $\times$ Chance-status [high-status, low-status]) between-subject experimental design. The critical dependent variable was participants' proportion of contributions $(\mathrm{PoC})$ in each round of the $\mathrm{PGG}$, which comprised 10 rounds in total. Participants' contributions from round to round were assessed. In addition, we recorded other dependent measure in a set of questions given before (demographics, personal stories, hobbies) and after the main task (estimates of similarity, estimates of empathy, believability of study, strategy development). The pre-questions requested details on age and gender, and questions concerning participant's positive (i.e. "Describe an event that has happened to you that has made you happy in the last year") and negative experiences (i.e. "Describe an event that has happened to you that has made you sad in the last year"), and their hobbies. Post-questions consisted of rating scales to assess participants judged similarity to, and empathy towards each of the three virtual players. The post-questions recorded participants' impression (similarity, empathizing) towards the three other virtual players on a 9-point scale, ranged from 1 (not at all) to 9 (very much). Participants' photos were taken at the start of the experiment using a phone camera that was uploaded on screen along with the photos of the three virtual players; these steps were designed to ensure that participants felt that all of the participants in the game were experiencing the same procedures, and were supposedly interacting with each other live online. The reasons for using virtual rather than real players was to allow for careful manipulations of the range of empathy and the impact it would have on the participants' behavior during the PGG. The three other virtual players' photos and profiles were made in 
advance, and piloted. Finally, debriefing questions were presented to participants to assess whether they believed that they were interacting with three other players online, and whether they recognized the three other players.

The PGG was programmed and implemented via a computer using E-prime 2.0 software. The game was arranged such that each participant was playing with three other players whose actual profiles including stories (regarding either negative events they experience, or their chosen hobbies) and photos were prepared in advance; this method is often referred to as "interaction deception". In the high-empathy condition, the three other players' profiles referred to a negative event that had been experienced (Player $1=$ a break up with a partner, Player 2 = a car accident, Player $3=$ a stolen mobile phone), which to some extent can be categorized as social pain/psychological pain. In addition, participants were instructed, "While you are reading this, try to imagine how the person felt about what they have just described. Try to imagine how the person feels as a result (i.e. perspective taking instruction), which was based on Batson \& Moran's (1999) empathy induction method. In the no-empathy condition, the profiles referred to neutral events (Player $1=$ swimming, Player 2 $=$ ride bicycle, Player 3 = running most mornings). There were no perspective-taking instructions as to how to read the profiles. Crucially, it is worth pointing out here that the empathy induction methods we used are perspective taking (Batson \& Moran, 1999; Epley, et al, 2006; Gilin, et al, 2012), which is more typically construed as cold empathy, rather than hot empathy (Loewenstein, 2000; Paal \& Bereczkei, 2007). In addition, while we tried to match the suffering stories with the neutral stories in terms of word length, and level of detail, it is possible that the suffering stories could be construed as more socially oriented than the neutral stories. In this regard, the emphasis in both suffering and neutral stories were couched in terms that made salient the experiences of the individual, rather than emphasising any social component of the stories in both sets. 
The assignment of participants to each experimental condition was carried out prior to the main experiment. The method by which we manipulated the high-status and low-status conditions was based on the endowments of the participant in each round. This study involved a status manipulation, in which half of the real participants were endowed with 30 tokens (high-status) and the other half were endowed with 10 tokens (low-status) on each round. All the three other virtual players were given 20 tokens per round regardless of highstatus or low-status group. Thereafter the allocation to empathy and no-empathy conditions was determined randomly. In this PGG program, the amount contributed by the three virtual players was fixed across for all participants and was based on the average contributions reported in Fehr and Gächter's study (2000) (taking into account the standard deviation) in the partner-treatment without punishment condition. The combined total contribution of the three virtual players on each round was as follows: 27, 34, 31, 24, 22, 23, 24, 18,12 and 10.

\section{Procedure}

Each participant was tested individually in a soundproofed experimental cubicle facing a computer monitor. After reading the information sheet and signing the consent form, participants were required to pick a ball from a black box without looking inside and were told the color of ball determined their assignment to an experimental condition. If they picked the red ball, the participants were assigned to the high-status condition; if they picked the blue ball, they were assigned to the low-status condition.

Next, the experimenter told the participant that since the experiment required them to work with three other players online together, they were required to do some preparation. "As we said in the information sheet, you are going to play this joint task with three other players online. We cannot let you talk with each other, since we need to conduct this study under controlled conditions. What we will do is exchange your profile with three other players. In order to do that, we need to collect your picture and some personal information." Having 
been informed that their data would be kept confidentially (i.e. only for the purposes of the experiment, after which there would be no basis on which an individual participant would be identifiable from the data collected), participants were asked to fill in the pre-questions, and to take a photo with a neutral facial emotion in front of a white walled background. Participants were then asked to wait for approximately 5 minutes and were told that the time was needed to coordinate the other players that were taking part in the experiment; this is where the interaction deception was involved. During this time participants were told to carefully read the instruction for the PGG. According to the color of ball they picked, they were given the corresponding instruction for that condition. In the high-status condition, the instruction explained that they wold be given 30 tokens per round, whereas in the low status condition, the instructions explained that participants would be given 10 tokens per round; in both cases, participants were made aware that the other participants would have 20 tokens per round.

The experimenter came back to the experimental cubicle after uploading the participants' picture to the computer running the PGG program. The experimenter asked the participants to explain the instructions in order to demonstrate their understanding of the task. Then the experimenter showed participants the three other players' pictures alongside their own picture. "These are the players you are going to play with, and you will see their profile in the program." To be more persuasive, the real participant picture was always the first picture to be presented, and the three other face photos followed. After entering some basic information (participants' number, gender, age), they were reminded of the instructions of the PGG. Then they were asked to wait for the experimenter to set up the other players, and on return, participants were instructed to press the SPACE key to get started.

In the PGG program, the high-empathy condition was presented with the empathy induction procedure. They were instructed: "Next you will see profiles of the three other 
participants who will work together with you. While you are reading this, try to imagine how the person felt about what they have just described. Try to imagine how it has affected them and how they feel as a result". In the no-empathy condition, participants were instructed: "Next you will see the profiles of three other participants who will work together with you." After these instructions all participants were consecutively presented with the picture and profile of each of the three players. After seeing the profiles, participants started the PGG. For each round when participants were required to decide on how many of their tokens to contribute, they were presented with the pictures of the three other players. In the high-status condition, it was from 0 to 30 tokens; whereas in the low-status condition, it was from 0 to 10 tokens. After they had made their decision, they entered their choice, and were required to wait between 4000 to $12000 \mathrm{~ms}$, randomly determined by the program. Then they were given feedback, “Other people contributed tokens: (the sum of three other players' contributions); Your contribution this round is: (the number of tokens they contributed); Your share of the pot for this round: (the total number of tokens they will receive on that round); and Your cumulative total of tokens across rounds (the total number they will receive across all rounds)". Then the program moved to the next round. This procedure was repeated until all 10 rounds were complete. Participants were required to copy down all the values presented on each round using a pen and form provided. The reason for this was to make sure that participants attended to all the feedback information presented on the screen on each round. On completion of the PGG, participants were then presented with the post questionnaires, and then the debrief questions, after which they were informed of details about the study, its purpose and the interaction deception issue. 
Results

Cohen (1988) provides a benchmark to define small (.1), medium (.3) and large (.5) effects where Cohen's $d$ is presented. Where effect sizes for partial $\eta^{2}$ are presented, the following broad classification is used to define small (.02), medium (.13) and large (.26) effects (Bakeman, 2005). In the analyses we presented in this and the remaining three experiments, we use these benchmarks to determine the size of the effects we report.

\section{Empathizing Manipulation Check}

For Experiment 1, an independent-samples $t$-test was conducted on judgments regarding the extent to which participants empathized with the experiences of the other players they were interacting with in the PGG in no-empathy $(n=49)$ and high-empathy $(n=$ 45) conditions. Empathizing judgments were higher in the high-empathy conditions $(M=$ $4.75, S D=1.44)$ compared to the no-empathy conditions $(M=3.71, S D=1.96),(d=-.604)$.

\section{Empathy \& Status manipulation}

The mean PoC in each of the 10 rounds in the four conditions for Experiment 1 are shown in Figure 1; the overall mean PoC for each condition is: high-status no empathy ( $M$ $=.44, S D=.18)$, low-status no empathy $(M=.56, S D=.18)$, high-status empathy $(M=.49$, $S D=.18)$, low-status empathy $(M=.55, S D=.18)$.

\section{Insert Figure 1}

In all analyses of contributions made in the PGG here and in the other three experiments, we analyse the proportion of contributions made, not the absolute values. The reason for this is that the total amounts that could be contributed differ in range given our manipulations of status. That is those in the high status conditions could contribute anything between 0 and 30 tokens on each round, those in the low status conditions could contribute anything between 0 and 10 tokens on each round, and respondents (though fictitious, but 
based on actual prior contributions reported by Fehr and Gächter's study (2000)) could contribute anything between 0 and 20 tokens. Given these differences, and to make sensible comparisons, the proportion of contributions of the endowment on each round were used in any analyses of PGG contributions.

A univariate analysis was conducted with $\mathrm{PoC}$ in the first round as a dependent variable, and empathy and chance-status as fixed-factor variables. There was a very small Chance-status $\times$ Empathy interaction on first round contributions $\left(\eta_{p}{ }^{2}=.001\right)$. There was a small main effect of empathy on PoCs $\left(\eta_{p}{ }^{2}=.02\right)$; and a small main effect of chancestatus on PoCs $\left(\eta_{p}{ }^{2}=.04\right)$. Focusing on PoCs across rounds, a $10 \times 2 \times 2$ (Round [1:10]), within-subject variable $\times($ Empathy [high-empathy, no-empathy] $) \times($ Chance-status [highstatus, low-status]) between-subject variables repeated-measures ANOVA was conducted. The interaction between chance-status and empathy was very small $\left(\eta_{p}{ }^{2}=.01\right)$ (see Figure 1). Also, there was also a very small main effect of empathy on PoCs, $\left(\eta_{p}{ }^{2}=.003\right)$. There was a small main effect of chance-status on PoCs (see Figure 1$),\left(\eta_{p}{ }^{2}=.06\right.$ ), and a small main effect of round, $\left(\eta_{p}{ }^{2}=.06\right)$, suggesting a general decrease in contributions across rounds. Overall, we found that across rounds the low-status group contributed more to the group pot compared to the high-status group.

Discussion

The key finding in Experiment 1 supported prediction 1, suggesting that the lowstatus group behaved more cooperatively than the high-status group. There was weak support for prediction 3 . That is, there were very small effects to suggest that the inducement of empathy increased contributions in the PGG; there was some evidence to support this when looking at first round contributions, but this was very small when looking across rounds.

In Experiment 1 status was determined by chance, in order to mimic situations in 
wealth is determined by lotteries. However, in real life setting status can also be determined by effort. Therefore, Experiment 2 was devised with two purposes in mind. First, the aim was to examine the extent to which the same pattern of results would be found under a different institution system of status acquisition, and to further examine the association between empathy and cooperation.

\section{Experiment 2}

In all respects but one, namely the way in which status was achieved, the design and procedure of Experiment 2 was identical to Experiment 1.

Method

\section{Participants}

Ninety-eight volunteers (71 females and 27 males) were recruited from Queen Mary University of London via emails and fliers. The mean age of the participants was 21.10 years (range from 18 to $44 ; S D=4.06$ ). The payments for participating were the same as Experiment 1 .

\section{Design and Materials}

Experiment 2 was a $2 \times 2$ (Empathy [high-empathy, no-empathy] $\times$ Effort-status [high-status, low-status]) between-subject experimental design. The critical dependent variable was also participants' $\mathrm{PoC}$ in the $\mathrm{PGG}$, of which 10 rounds in total, as with Experiment 1 . The digit cancellation test is a $23 \times 40$ matrix which was generated using Matlab software (http://uk.mathworks.com/products/matlab/). There are 106 number threes in total in the matrix, and participants were presented with matrix on a printed A4 piece of paper and had to cross out as many number threes in two minutes. The score 94 was obtained based on piloting the test. Prior to the pilot, the number was set at 84 since this was the median of a 
group $(n=55, M d n=84.00, M=80.17, S D=1.58)$ conducting the experiment. However, when initially carrying out the experiment, most participants (10 out of 12) achieved above the 84 threshold, and so this means that most of the participants were performing at celling, and so this threshold did not meaningfully discriminate performance. Therefore, after these 12 participants, we increased the threshold to 94 , which was calculated based on mean achieved by the piloted high-status group $(n=10, M d n=95.5, M=93.60, S D=5.13)$. Those achieving a score equal to or above 94 were allocated to the high-status condition, and those scoring less than 94 were allocated to the low-status condition. Thereafter the allocation to empathy and no-empathy conditions was determined randomly. All participants were informed of the allocation procedure prior to performing the test. With the exception of the allocation procedure, in all other respects Experiment 2 was identical to Experiment 1.

\section{Procedure}

In Experiment 2, participants were required to perform a digit cancellation test instead of picking a color ball in a black box to allocate them into high-status or low-status conditions. Apart from this, all other experimental procedures were exactly the same as the Experiment 1.

Results

\section{Empathizing Manipulation Effectiveness Check}

The same analysis conducted in Experiment 1 was conducted on empathy judgments for Experiment 2 on the no-empathy $(n=52)$ and high-empathy $(n=46)$ conditions. There was a large effect $(d=1.31)$ indicating that empathy judgments were higher in the highempathy condition $(M=6.20, S D=1.73)$ compared to the no-empathy conditions $(M=3.97$, $S D=1.67)$ 


\section{Empathy \& Status manipulation}

The mean $\mathrm{PoC}$ in each of the 10 rounds in the four conditions for Experiment 2 are shown in Figure 2; the overall mean PoC for each condition is: high-status no empathy ( $M$ $=.38, S D=.21)$, low-status no empathy $(M=.47, S D=.21)$, high-status empathy $(M=.31$, $S D=.21)$, low-status empathy $(M=.60, S D=.21)$.

The same analyses were conducted as Experiment 1. There was a medium to large effect found for the interaction between effort-status and empathy for PoCs on the first round $\left(\eta_{p}{ }^{2}=.18\right)$. There was a very small effect of empathy on first round PoCs $\left(\eta_{p}{ }^{2}=.01\right)$, but there was a medium effect of effort-status $\left(\eta_{p}{ }^{2}=.14\right)$. A $10 \times 2 \times 2$ (Round [1:10]), withinsubject variable $\times($ Empathy [high-empathy, no-empathy] $) \times($ Effort-status [high-status, lowstatus]) between-subject variables repeated-measures ANOVA was conducted (See Figure 2). There was a small effect found in the interaction between effort-status and empathy $\left(\eta_{p}{ }^{2}\right.$ $=.06)$. There was very small effect of empathy $\left(\eta_{p}{ }^{2}=.004\right)$. There was a medium to large main effect of effort-status on PoCs across rounds $\left(\eta_{p}{ }^{2}=.18\right)$. Since there was some evidence of interaction effects, post-hoc pairwise comparisons were conducted, which found that in the high-empathy condition, the effect was large and suggested that the low-status condition contributed more than those in the high-status condition, $\left(\eta_{p}{ }^{2}=.20\right)$; in the no-empathy condition, the effect on PoCs across rounds based on differences in status was small $\left(\eta_{p}{ }^{2}\right.$ $=.03$ ) also suggesting that the low status condition contributed more than the high-status condition. There was a small interaction effect between round and effort-status $\left(\eta_{p}{ }^{2}=.03\right)$, and a small main effect of round suggesting that contributions decreased across rounds, $\left(\eta_{p}{ }^{2}\right.$ $=.04)$.

\section{Insert Figure 2 about here}

In addition, we compared the PoCs contributed across rounds for high-status conditions in which their status was gained through effort (Experiment 2), with high-status 
conditions in which their status was gained through chance (Experiment 1). A $10 \times 2$ (Round [1:10]), within-subject variable $\times 2$ (Gained-status [high-status-effort, high-status-chance]) between-subject variables repeated-measures ANOVA was conducted. There was a small effect $\left(\eta_{p}{ }^{2}=.05\right)$ suggesting that those in the high-status-effort conditions ( $\mathrm{n}=47, M=.37$, $S D=.22)$ contributed less than the high-status-chance conditions ( $\mathrm{n}=49, M=.46, S D=.18)$,

Discussion

Consistent with Experiment 1, Experiment 2 supported prediction 1. In general, those in the low-status group showed more cooperation than those in the high-status group as indexed by the level of tokens contributed in the PGG. In addition, in support of prediction 2, the evidence suggested that when high-status was achieved through effort, contributions were consistently lower than when achieved through chance. While there were very small effects in support of prediction 3 consistent with Experiment 1, Experiment 2 did however reveal an interaction between empathy and status. For those in the low-status group high-empathy condition there was evidence that they showed greater levels of cooperation than those in the low-status no-empathy group; there was also very small effects suggesting the same pattern in the no-empathy status conditions. Thus far, given the very small effects revealing an association between empathy and cooperation in both Experiment 1 and 2, Experiment 3 was conducted to fully explore the empathy-cooperation link.

\section{Experiment 3}

Experiment 3 was designed to examine the link between empathy and cooperation under equal resources conditions (Yamamoto \& Takimoto, 2012) as a way to establish the extent to which the empathy-cooperation link is reliable independent of the manipulation of status. 
Method

\section{Participants}

Sixty-nine volunteers (47 females and 22 males) were recruited from Queen Mary University of London. Participants were aged between 18 to 56 years old $(M=22.68, S D=$ 5.65). On completion of the experiment, participants received between $£ 6$ and $£ 15$ ( $\$ 8.41$ to $\$ 21.02)$ based on their performance in the linear PGG $(25$ tokens $=£ 1)$. They were randomly allocated to one of three conditions (high-empathy, low-empathy, no-empathy) by a randomly generated number in excel.

\section{Design and Materials}

Experiment 3 was a between-subject design with 3 levels (empathy [high-empathy, low-empathy, no-empathy]) experimental design, and the critical dependent variable was participants' PoC per round in the main PGG, of which there were 10 rounds in total. The high-empathy and no-empathy conditions were the same as in Experiment 1 and Experiment 2. In the low-empathy condition participants read the same profiles as those in the highempathy condition, but they were instructed, "While you are reading this, try to take an objective perspective towards what has just been described. Try to remain as objective and detached as possible." This served as an intermediate level of empathy induction based on previous empathy induction techniques (1999). With this exception, and the fact that all participants received the same endowment as the virtual players on each round $[20,20,20,20]$, in all other respects Experiment 3 was the same as Experiment 1 and 2.

\section{Procedure}

After the participants completed reading the information sheet and signed the consent form, participants were randomly assigned into one of three conditions. In all other respects Experiment 3 was the same as Experiment 1 and 2. 
Results

\section{Empathizing Manipulation Effectiveness Check}

For Experiment 3, a one-way ANOVA was conducted using mean estimates of empathy. The analysis revealed a main effect of empathy, suggesting that across the three conditions participants self-assessed empathizing varied $\left(\eta_{p}{ }^{2}=.18\right)$. Self-reported empathizing was higher $(d=.69)$ in the high-empathy $(M=5.40, S D=1.41)$ compared with the no-empathy condition $(M=4.04, S D=2.37)$, and higher $(d=2.09)$ in the low-empathy $(M=5.93, S D=1.77)$ compared to no-empathy. There was also a difference between high and low-empathy conditions, suggesting that self-assessed empathising was higher $(d=.33)$ in the low empathy condition compared to the high empathy condition.

\section{Empathy manipulation}

The mean PoC in each of the 10 rounds in the four conditions for Experiment 3 are shown in Figure 3; the overall mean PoC for each condition is: high empathy $(M=.44, S D$ $=.22)$, low-empathy $(M=.44, S D=.22)$, and no empathy $(M=.47, S D=.22)$.

Insert Figure 3 about here

First round data for Experiment 3 was used for one-way ANOVA to explore the main effect of empathy, for which there was a very small effect $\left(\eta_{p}^{2}=.001\right)$. Next a $3 \times 10$ (Round ([1:10], within-subject variable $\times$ Empathy [high-empathy, low-empathy, no-empathy] between subjects variable) repeated-measures ANOVA was conducted. There was a medium main effect of round, $\left(\eta_{p}{ }^{2}=.13\right)$, suggesting that contributions generally decreased across rounds. There was a very small main effect of empathy on PoCs across rounds $\left(\eta_{p}{ }^{2}=.004\right)$ (see Figure 4), and there was a very small interaction effect between round and empathy $\left(\eta_{p}{ }^{2}\right.$ $=.01)($ see Figure 3) 


\section{Overall Deception Success Check}

At this stage we examine data from all three experiments in order to assess the extent to which the deception introduced in our study impacted on any of the behavioral measures we recorded. Taking all of the participants into account across all three experiments we had 184 data points having excluding those reported 'unsure' in our debrief questionnaire, or where there was missing data. Of the 184 data points we include in our analyses participants either answered Yes, they believed that the experimental set-up was as we had described (i.e. that they were playing with 3 other real participants), or No they did not believe our experimental set-up, and were unconvinced that they were interacting with 3 other participants in the PGG. Across all three experiments, $40 \%$ of participants responded No in our debrief questionnaire. A Round (1-10) x Deception success (yes 1, no 2) repeatedmeasures ANOVA was conducted. The results found that the interaction between round and deception revealed a very small effect on contributions in PGG $\left(\eta_{p}{ }^{2}=.00001\right)$.

Discussion

Consistent with Experiments 1 and 2, Experiment 3 found very small effects in support for Predictions 3, and there was also a very small effect in support for Prediction 4. In line with previous studies (Batson \& Ahmad, 2001; Batson \& Moran, 1999; Rumble et al., 2010), we used a similar design in which one participant is interacting with 3 fictitious individuals. The very small effects revealed that this did not adversely impact the pattern of contributions in the three experiments included in this study. Nevertheless, to fully test our manipulations regarding status and empathy, we considered it of importance to examine the extent to which our findings would replicate in an experiment in which participants were interacting with real players. 


\section{Experiment 4}

Experiment 4 used a 2-player PGG, in which the set up was the same as a typical 4player game, but with 2-players, in which status (low-status, equal-status) was achieved based on chance using the same procedure as that of Experiment 1 . The rationale for the changes in design are as follows. First, we consider it of important to examine the extent to which our pattern of results generalize to situations in which real players are facing a genuine social interaction with other real players. Second, thus far we have not conducted a direct comparison between a control status condition with a status manipulation. Therefore, given that we found small to medium effects for low status conditions in Experiment 1 and 2, we examined the extent to which low status conditions contributed more than conditions in which the endowment was the same for both players (i.e. equal-status).

Method

\section{Participants}

One hundred and sixty volunteers (87 females and 73 males) were recruited from Queen Mary University of London. The mean age of the participants was 22.86 years (range from 18 to 50; $S D=4.97$ ). The payments for participating were the same as Experiment 1 and 2.

\section{Design and Materials}

Experiment 4 was a $2 \times 2$ (Empathy [high-empathy, no-empathy] $\times$ chance-status [low-status, equal-status]) between-subject experimental design. The critical dependent variable was also participants' $\mathrm{PoC}$ in the $\mathrm{PGG}$, of which there were a 10 rounds in total, as with Experiment 1 and 2. The basis on which participants were allocated to the following four conditions was the same as Experiment 1: high-status no-empathy, high-status empathy, low-status no-empathy, and low-status empathy. 


\section{Procedure}

The pairs of participants were tested together in a sound-proofed experimental cubicle facing two individual computer monitors with a dividing folding screen. Participants were randomly allocated to Player A or Player B based simply on the first person to enter the cubicle; the first person was allocated to Player A, and the other person was allocated to Player B. After reading the information sheet and signing the consent form, one of the two players was asked to volunteer to pick a ball from a black box without looking. If they picked the red ball, the participant was assigned as equal-status [20 tokens; 20 tokens]; if they picked the blue ball, they were assigned as low-status [10 tokens: 20 tokens]. After that, they were allowed to start the experiment. Once seated and allocated to their roles, all remaining procedures were identical to Experiment 1.

Results

\section{Empathizing Manipulation Effectiveness Check}

An independent-samples $t$-test was conducted on judgments regarding the extent to which participants empathized with the experiences of the other player in the no-empathy and high-empathy conditions. Empathizing judgments were higher $(d=-1.25)$ in the highempathy condition $(n=80, M=7.40, S D=1.57)$ compared to the no-empathy condition $(n=$ $80, M=4.75, S D=2.53)$.

\section{Empathy manipulation}

The mean PoC in each of the 10 rounds in the four conditions for Experiment 4 are shown in Figure 4; the overall mean PoC for each condition is: equal-status no empathy ( $M$ $=.52, S D=.30)$, low-status no empathy $(M=.56, S D=.26)$, equal-status empathy $(M=.56$, $S D=.31)$, low-status empathy $(M=.69, S D=.29)$. 
Insert Figure 4 about here

Looking at differences between conditions across both players, based on first round contributions. A Univariate analysis was conducted and revealed a very small main effect of empathy $\left(\eta_{p}{ }^{2}=.000001\right)$. There was a small main effect of status, $\left(\eta_{p}{ }^{2}=.02\right)$ suggesting that those in the low-status condition $(M=.62, S D=.36)$ contributed more than the equalstatus condition $(M=.60, S D=.36)$. There was a very small effect of an interaction between empathy and status $\left(\eta_{p}{ }^{2}=.001\right)$.

Focusing on PoCs across rounds, a $10 \times 2 \times 2$ (Round [1:10]), within-subject variable $\times($ Empathy [high-empathy, no-empathy] $) \times($ Chance-status [low-status, equal-status] $)$ between-subject variables repeated-measures ANOVA was conducted (see Figure 4). There was a very small effect of an interaction between chance-status and empathy $\left(\eta_{p}{ }^{2}=.006\right)$. There was a small main effect of empathy $\left(\eta_{p}{ }^{2}=.02\right)$, and a small main effect of status $\left(\eta_{p}{ }^{2}=\right.$ .02). There was also a small main effect of round $\left(\eta_{p}{ }^{2}=.03\right)$, suggesting that contributions generally decreased across rounds. Overall, we found that across rounds there was a trend suggesting that the low-status group contributed more to the group pot compared to the equal-status group.

Looking at contributions across rounds, for Player A only, a $10 \times 2 \times 2$ (Round $[1: 10])$, within-subject variable $\times($ Empathy [high-empathy, no-empathy] $) \times($ Condition [lowstatus; equal-status]) between-subject variables repeated-measures ANOVA was conducted. There was small effect of an interaction between chance-status and empathy $\left(\eta_{p}{ }^{2}=.02\right)$. There was a small main effect of empathy $\left(\eta_{p}{ }^{2}=.05\right)$, and a small main effect of status $\left(\eta_{p}{ }^{2}=\right.$ .03). There was also a small main effect of round $\left(\eta_{p}{ }^{2}=.04\right)$. Again, we found that across rounds there was a trend suggesting that low-status players contributed more to the group pot compared to the equal-status players. 
The same analyses were conducted for Player B. There was small effect of an interaction between chance-status and empathy $\left(\eta_{p}{ }^{2}=.02\right)$. There was a very small main effect of empathy $\left(\eta_{p}{ }^{2}=.008\right)$. There was a small main effect of round $\left(\eta_{p}{ }^{2}=.06\right)$. There was also a small main effect of status $\left(\eta_{p}{ }^{2}=.02\right)$ suggesting that low-status players contributed more to the group pot compared to the equal-status players.

Discussion

Experiment 4 was designed to extend the findings reported in Experiment 1 and 2 under conditions in which participants were taking part in a genuine social interaction in a PGG. Experiment 4 replicated the findings of Experiment 1 in a 2-player PGG. Overall, the findings suggest that those in the low-status group contributed more than those in the equalstatus group. There was also some evidence to suggest across rounds, the empathy induction method lead to increases in contributions for the empathy conditions compared to the no empathy induction conditions.

\section{Summary and Concluding Discussion}

The main objective of this study was to examine the following two questions: 1) To what extent are pro-social behaviors impacted in situations in which the resources gained (either through chance or effort) by one individual in the group differ? 2) To what extent does empathy promote pro-social behaviors given the way in which one individual in a group achieves their status (i.e. through chance or effort)? Overall, the findings from four experiments suggest that, individuals with less resources than their group members (lowstatus) tend to be more cooperative compared to individuals that have more resources than their group members (high-status), and those with equal resources (equal-status). In addition, we found that any attempts to induce empathy in individuals resulted in very small effects on cooperative behaviors. In the discussion that follows, we consider the evidence 
specifically in relation to the four predictions we tested, and the implications of our findings with respect to previous theoretical and empirical work.

Prediction 1: Informed by prior empirical (Bennett, 2012; Cote, House, \& Willer, 2015; Guinote, et al., 2015; Piff, et al., 2010) and theoretical work (Kafashan et al., 2014) examining the relationship between status and pro-social behaviors, we predicted the following: Overall low-status individuals will show greater cooperation, as evidenced through contributions to a public good, compared to high-status individuals. We found support for this in Experiment 1 in which status was gained through chance, and in Experiment 2 in which status was gained through effort. In addition, we found support for this in Experiment 4 in which low-status conditions tended to contribute more compared to equal-status conditions.

As Kafashan et al., (2014) proposed, possessing status can change the perceived costs and benefits of engaging in pro-social behavior, and so we consider in more depth how this emerged in our present pattern of findings. First, it may be the case that low-status groups behaved cooperatively because they may have outweighed the cost of increasing contributions against the gains of increasing their reputation amongst the group. This is consistent with work suggesting that low status individuals do indeed try to improve their standing in a social hierarchy (Willer, 2009b), or as a means of affiliating themselves with a perceived group identity (Kraus, Piff, \& Keltner, 2009). Second, it may also be the case that the cost of behaving more cooperatively was outweighed by the benefits of demonstrating compassion to other group members. Consistent with this, there is evidence to suggest that, compared to high-status groups, there is a stronger association between low-status individuals and expressions of charitable and helping behaviors (Stellar, Manzo, Kraus, \& Keltner, 2012). Moreover, this also implies that compared to high-status groups, low-status groups have stronger feelings of compassion because they are more sensitive to a sense of fairness. 
This may also potentially help to explain why it is that we found an effect of empathy on cooperation was high localized to low-status groups in Experiment 2 in which status was gained by effort. As mentioned, one reason may be that this group show greater compassion and are more sensitive to fairness (Kraus et al., 2009), but this doesn't explain why empathy revealed larger effects in the low effort-status groups (Experiment 2) than low chance-status groups (Experiment 1 and 4).

One possible explanation is based on the differences in control that people experienced (Osman, 2014). When the mechanism by which resources are allocated is via chance, then clearly there is no sense of control or real ownership that people can feel with regards to having more or less than others (unless one experiences an illusion of control). In contrast, when resources are achieved through effort, then people are likely to feel greater ownership and responsibility over the resources they acquired, and that the manner by which they acquired them was under their control. Some have argued that limited control over the attainment of resources leaves low-status individuals, as compared to high-status individuals, more dependent on others (Piff et al., 2010), which in turn encourages more cooperative behavior. If experienced lack of control amplifies cooperation because now there is a dependence on others to show cooperative behaviors, taken together with some sense of empathy, then we would expect those in the low-status group to show greater cooperative behaviors than the high-status group in the chance-status condition, which is also what we found. What is hard to determine is whether differences in behavior resulting from acquiring status through effort or chance is a matter of degree (i.e. levels of control), or a matter of kind (i.e. control vs. no control).

Prediction 2: Again, informed by previous empirical work (e.g., Hays \& Blader, 2016), and specifically extending the theoretical claims made by Kafashan et al.'s (2014) bidirectional causation account of status and cooperation, we considered the extent to which the 
costs and benefits of cooperative behavior was impacted by the way in which status was achieved. Based on this, we tested the following: If perceived entitlement plays a role, then high status individuals will feel more entitled when they achieve their status through effort than when achieved through chance, and so will display lower levels of cooperation through contributions to a public good compared to high-status individuals achieving their status through chance. To this end, we found support for this. When comparing the contributions across rounds, those in the high-status condition that had earned their status via effort contributed consistently less than those that had achieved their status via chance. This suggests that, consistent with prior work suggesting that high-status individuals often make pro-social choices with respect to their perceived entitlement and self-interests (Cherry \& Shogren, 2008; Cote, House, \& Willer, 2015; Hays \& Blader, 2016), those that had earned their status considered the costs of contributing higher than those that gained their status chance.

Prediction 3: There is considerable work suggesting a role for empathy in promoting pro-social behaviors, particularly cooperation (Batson, 2011; Cialdini, et al., 1982; Rumble et al., 2010; Yamamoto \&Takimoto, 2012), and several empirical studies supporting this view (Allsop, et al., 2002; Batson \& Moran, 1999; Cialdini et al., 1987; Eimontaite, et al., 2013; Fultz, et al., 1986; Oswald, 1996, 2002; Pavey, et al., 2012; Stürmer, et al., 2006). Given the general theoretical claims that, while they differ with respect to the underlying mechanism that drives the relationship, generally empathy promotes cooperation. Therefore, we tested the following: Overall, when perspective taking inducements of empathy are present, irrespective of status manipulations, there should be greater displays of cooperation through contributions to a public good compared to no-empathy inducements. We found very small effects of empathy on cooperative behaviors in the PGG in Experiments 1, 2. In fact, on this basis Experiment 3 was run specifically to test the role of empathy induction without the 
status manipulation, to check whether this may have muted the expression of empathy on cooperation. Here too we found very small effects. In Experiment 4 we did find a small effect suggesting that empathy promoted cooperation.

First of all, as discussed earlier, there is also evidence that challenges this received view, suggesting instead that empathy has a limited (LV et al., 2015; Oswald, 1996; Warren \& Walker, 1991; Xu et al., 2012, Study 2), or even a negative effect on pro-social behaviors (Epley, et al., 2006; Gilin et al., 2012). So, in this light, our findings are consistent with evidence suggesting weak effects of empathy on cooperation. Second, given that we did find small effects of the impact of empathy induction on cooperation in Experiment 2, albeit highly localized to the low-status group, as well as in Experiment 4, we consider the basis for this.

One key reason for the very small impact of empathy on cooperation may be explained by the fact that empathy inducing altruism operates effectively on a local individual level rather than on a multiple agent level. Thus, when the target of empathetic feelings is ambiguous, then this leads to a "escaping effect" (Cameron \& Payne, 2011) such that the degree of compassion people feel tends to decrease as the number of people in need increases. "One death is a tragedy; one million is a statistic." This suggests that there may be an upper bound to empathizing abilities, which is consistent with evidence demonstrating that reliably inducing empathy to increase cooperation is most commonly found in dyads (Batson \& Moran, 1999). Our pattern of findings from Experiment 4 support this speculation.

An alternative simple explanation might be that our dependent variable was not sufficiently sensitive enough to detect a weak empathy manipulation. There are two simple counters to this limitation, the first is that previous studies, discussed in the next point, have used the same experimental methods and have detected an effect of empathy, albeit a temperamental one. The second is that, the same dependent variable used in the three 
experiments in which status was manipulated, was sufficiently sensitive enough to detect small to large effects of status on contributions in the PGG.

A further reason for why our empathy induction method only very weakly promoted cooperative behaviors was because of the particular method we used. The empathy induction method adopted here, and in many other studies, is the perspective-taking method in which participants are instructed to consider the experiences of others via descriptions of people's suffering (Allsop et al., 2002; Cialdini et al., 1987; Eimontaite et al., 2013; Pavey et al., 2012; Stürmer et al., 2006), a form of cold empathy (Loewenstein, 2000; Paal \& Bereczkei, 2007). This means that they may have been successful in understanding the behaviors and emotional states of others, but they did not necessarily adopt the same emotional states of others. This is in contrast to experimental methods designed to induce hot empathy in which participants are presented with videos of people experiencing bad situations (Oswald, 1996), or even invited to directly helping others in need (Oswald, 2000), that more directly induces strong feelings of sadness or empathic concern. Therefore, it may simply be the case, that hot empathy which induces actual changes in emotional states is a more effective means of promoting cooperative behaviors than cold empathy. Though one caveat to this is that, the mixed findings concerning the impact of empathy on cooperation specifically concern perspectivetaking methods, in which some studies show a positive influence, and others do not. Which suggests that either the technique is unreliable, or the general impact of empathy on cooperation is simply less straightforward than has been claimed (Yamamoto \&Takimoto, 2012).

Prediction 4: For this reason discussion previously, we sought to test Yamamoto and Takimoto's (2012) fairness and empathy account, in which they claim that empathy promotes prosocial behaviors under conditions of fairness. From this, we tested the following prediction: If a sense of fairness is used to complement empathy in supporting cooperative 
behaviors, then under conditions in which empathy inducements are present, there should be evidence of an impact of empathy on cooperation under conditions in which the status of individuals is equal (i.e. fair), rather than unequal (unfair). We found very small effects in support for this prediction. In the equal resource conditions in which everyone was endowed with the same number of tokens in the group (Experiment 3, and Experiment 4, equal status group), there were very small to small effects to suggest an effect of empathy on cooperation. Again, one speculation for this is that the type of empathy inducement technique that was used in this study was not strong enough as compared to methods that induce hot empathy. A second more nuanced explanation is that, rather than promote cooperation, our empathy manipulation, in association with other factors, helped to stabilize cooperative behaviors across rounds. However, in all four experiments, contributions reduced across rounds, and there were only very small effects to suggest an interaction with empathy and contributions across rounds.

Another contributing factor regarding the very small effect of empathy on cooperation in our study concerns a key novel strength of the present study regarding the use of real financial incentives. When developing our paradigm, we took heed of critical comments from the behavioral economics literature regarding incentives schedules that are in line with the aims of the specific task or game (Hertwig \& Ortmann, 2001). In contrast, participants in many previous studies which found empathy-induced cooperation obtained either a fixed show-up fee (Xu et al., 2012) or course credits for their attendance (Batson et al., 1995; Batson \& Moran, 1999; Rumble et al., 2010). In our experiments participant payments were directly associated with their choice-behavior. Even though empathy-induced altruism may appear to promote cooperation (Batson \& Moran, 1999), it may only be the case for studies in which payment is not dependent on actual choice behavior. Thus, the cost of 
cooperative behavior may be actually rather high such that empathy is not strong enough to override a self-maximizing strategy (Ma-Kellams \& Blascovich, 2013).

In summary, status and the way in which it is achieved (chance, effort) appeared to be a key determining factor in the level of cooperation observed in a multiplayer game. In particular, those with less resources than their counterparts tended to be more cooperative than those with more resources than their counterparts. The present study found very small effects to support the general intuition of the impact of empathy on cooperation under previously unexplored conditions of inequality of resources. One reason for the very small effect of empathy on cooperation under conditions in which people gain different levels of status, is that strong emotional experiences of empathic concern towards others need to ameliorate more salient factors, such as, for those with high status, maintaining personal finances achieved through effort as well as chance. 


\section{References}

Abele, S., Stasser, G., \& Chartier, C. (2010). Conflict and coordination in the provision of public goods: A conceptual analysis of continuous and step-level games. Personality and Social Psychology Review, 14(4), 385-401. doi:10.1177/1088868310368535

Ainsworth, S. E., \& Baumeister, R. F. (2013). Cooperation and fairness depend on self-regulation. Behavioral and Brain Sciences, 36(1), 79-80.

Andreconi, J. (1995). Cooperation in public goods experiments: Kindness or confusion. The American Economic Review, 85(4), 891-904.

Bakeman, R. (2005) Recommended effect size statistics for repeated measure designs. Behavior Research Methods, 37, 379-384. doi:10.3758/BF03192707;

Batson, C. D. (1991). The altruism question: Toward a social psychological answer. New York: Lawrence Erlbaum.

Batson, C. D. (1994). Why act for the public good? Four answers. Personality and Social Psychology Bulletin, 20(5), 603-610. doi:10.1177/0146167294205016

Batson, C. D. (2011). Altruism in humans. New York: Oxford University Press.

Batson, C. D., \& Ahmad, N. (2001). Empathy-induced altruism in a prisoner's dilemma II: What if the target of empathy has defected? European Journal of Social Psychology, 31(1), 25-36. doi:10.1002/ejsp.26

Batson, C. D., Ahmad, N., Yin, J., Bedell, S. J., Johnson, J. W., Templin, C. M., \& Whiteside, A. (1999). Two threats to the common good: Self-interested egoism and empathy-induced altruism. Personality and Social Psychology Bulletin, 25(1), 3-16. doi:10.1177/0146167299025001001

Batson, C. D., Batson, J. G., Todd, R. M., Brummett, B. H., Shaw, L. L., \& Aldeguer, C. M. R. (1995). Empathy and the collective good: Caring for one of the others in a social dilemma. Journal of Personality and Social Psychology, 68(4), 619-631. doi:10.1037/00223514.68.4.619 
Batson, C. D., \& Moran, T. (1999). Empathy-induced altruism in a prisoner's dilemma. European Journal of Social Psychology, 29(7), 909-924. doi:10.1002/(SICI)10990992(199911)29:7<909::AID-EJSP965>3.0.CO;2-L

Beadle, J. N., Sheehan, A. H., Dahlben, B., \& Gutchess, A. H. (2013). Aging, empathy, and prosociality. The Journals of Gerontology Series B: Psychological Sciences and Social Sciences, gbt091.

Bennett, R. (2012). Why urban poor donate a study of low-income charitable giving in London. Nonprofit and Voluntary Sector Quarterly, 41(5), 870-891. doi:10.1177/0899764011419518

Bixenstine, V. E., \& Douglas, J. (1967). Effect of psychopathology on group consensus and cooperative choice in a six-person game. Journal of Personality and Social Psychology, 5(1), $32-37$.

Bothner, M. S., Kim, Y. K., \& Smith, E. B. (2012). How does status affect performance? Status as an asset vs. status as a liability in the PGA and NASCAR. Organization Science, 23(2), 416-433.

Brosnan, S. F., \& de Waal, F. B. (2014). Evolution of responses to (un)fairness. Science, 346(6207), 1251776. doi:10.1126/science. 1251776

Cameron, C. D., \& Payne, B. K. (2011). Escaping affect: How motivated emotion regulation creates insensitivity to mass suffering. Journal of Personality and Social Psychology, 100(1), 1-15.

Cherry, T. L., Kroll, S., \& Shogren, J. F. (2005). The impact of endowment heterogeneity and origin on public good contributions: Evidence from the lab. Journal of Economic Behavior \& Organization, 57(3), 357-365. doi:10.1016/j.jebo.2003.11.010

Cherry, T. L., \& Shogren, J. F. (2008). Self-interest, sympathy and the origin of endowments. Economics Letters, 101(1), 69-72. doi:10.1016/j.econlet.2008.04.007

Choshen-Hillel, S., \& Yaniv, I. (2011). Agency and the construction of social preference: Between inequality aversion and prosocial behavior. Journal of Personality and Social Psychology, 101(6), 1253-1261. doi:10.1037/a0024557

Christensen, L. (1988). Deception in psychological research when is its use justified? Personality and Social Psychology Bulletin, 14(4), 664-675. doi:10.1177/0146167288144002 
Clark, J. (2002). House money effects in public good experiments. Experimental Economics, 5(3), 223-231. doi:10.1023/A:1020832203804

Cohen, T. R., \& Insko, C. A. (2008). War and peace: Possible approaches to reducing intergroup conflict. Perspectives on Psychological Science, 3(2), 87-93. doi:10.1111/j.17456916.2008.00066.x

Cote, S. (2011). How social class shapes thoughts and actions in organizations. Research in Organizational Behavior, 31, 43-71. doi:10.1016/j.riob.2011.09.004

Cote, S., House, J., \& Willer, R. (2015). High economic inequality leads higher-income individuals to be less generous. Proceedings of the National Academy of Sciences of the United States of America, 112(52), 15838-15843. doi:10.1073/pnas.1511536112

Dannenberg, A., Riechmann, T., Sturm, B., \& Vogt, C. (2012). Inequality aversion and the house money effect. Experimental Economics, 15(3), 460-484. doi:10.1007/s10683-011-9308-2

De Cremer, D., Snyder, M., \& Dewitte, S. (2001). ‘The less I trust, the less I contribute (or not)?' The effects of trust, accountability and self-monitoring in social dilemmas. European Journal of Social Psychology, 31(1), 93-107. doi:10.1002/ejsp.34

Fehr, E., \& Gächter, S. (2000). Cooperation and punishment in public goods experiments. Institute for Empirical Research in Economics Working Paper, 90(4), 980-994. doi:10.1257/aer.90.4.980

Fehr, E., \& Gächter, S. (2002). Altruistic punishment in humans. Nature, 415, 137-140. doi:10.1038/415137a

Fehr, E., \& Schmidt, K. M. (2000). Theories of fairness and reciprocity-evidence and economic applications.

Hays, N. A., \& Blader, S. L. (2017). To give or not to give? Interactive effects of status and legitimacy on generosity. Journal of personality and social psychology, 112(1), 17-39.

Guinote, A., Cotzia, I., Sandhu, S., \& Siwa, P. (2015). Social status modulates prosocial behavior and egalitarianism in preschool children and adults. Proceedings of the National Academy of Sciences of the United States of America, 112, 731-736. http://dx.doi.org/10.1073/pnas .1414550112 
Glyn, A. (1994). Paying for inequality: The economic cost of social injustice: Institute for Public Policy Research.

Henrich, J., Chudek, M., \& Boyd, R. (2015). The Big Man Mechanism: how prestige fosters cooperation and creates prosocial leaders. Philosophical Transactions of the Royal Society $B, 370(1683), 20150013$.

Hertwig, R., \& Ortmann, A. (2001). Experimental practices in economics: A methodological challenge for psychologists? Behavioral and Brain Sciences, 24(3), 383-403.

Joireman, J. A., Kuhlman, D. M., Van Lange, P. A. M., Doi, T., \& Shelley, G. P. (2003). Perceived rationality, morality, and power of social choice as a function of interdependence structure and social value orientation. European Journal of Social Psychology, 33(3), 413-437. doi:10.1002/ejsp.155

Kafashan, S., Sparks, A., Griskevicius, V., \& Barclay, P. (2014). Prosocial behavior and social status The Psychology of Social Status (pp. 139-158). New York: Springer Science \& Business Media.

Kamas, L., \& Preston, A. (2012). Distributive and reciprocal fairness: What can we learn from the heterogeneity of social preferences? Journal of Economic Psychology, 33(3), 538-553. doi:10.1016/j.joep.2011.12.003

Kelley, H. H., \& Thibaut, J. W. (1978). Interpersonal relations: A theory of interdependence. New York: Wiley.

Komorita, S. S., Parks, C. D., \& Hulbert, L. (1992). Reciprocity and the induction of cooperation in social dilemmas. Journal of Personality and Social Psychology, 62(4), 607-617. doi:10.1037/0022-3514.62.4.607

Kraus, M. W., Piff, P. K., \& Keltner, D. (2009). Social class, sense of control, and social explanation. Journal of Personality and Social Psychology, 97(6), 992-1004. doi:10.1037/a0016357

Kraus, M. W., \& Stephens, N. M. (2012). A road map for an emerging psychology of social class. Social and Personality Psychology Compass, 6(9), 642-656. doi:10.1111/j.17519004.2012.00453.x 
Kroll, S., Cherry, T. L., \& Shogren, J. F. (2007). The impact of endowment heterogeneity and origin on contributions in best-shot public good games. Experimental Economics, 10(4), 411-428. doi:10.1007/s10683-006-9144-y

Lind, E. A., \& van den Bos, K. (2002). When fairness works: Toward a general theory of uncertainty management. Research in Organizational Behavior, 24, 181-224.

Loury, G. C. (1981). Is equal opportunity enough? The American Economic Review, 122-126.

L. V., J., Proulx, M. J., \& Osman, M. (2015). The Role of Personal Values and Empathy in a Cooperative Game. Journal of Social Science Research, 9(2), 1834-1844.

Ma-Kellams, C., \& Blascovich, J. (2013). The ironic effect of financial incentive on empathic accuracy. Journal of Experimental Social Psychology, 49(1), 65-71. doi:10.1016/j.jesp.2012.08.014

McClelland, D. C. (1985). How motives, skills, and values determine what people do. American Psychologist, 40(7), 812-825. doi:10.1037/0003-066x.40.7.812

Muehlbacher, S., \& Kirchler, E. (2009). Origin of endowments in public good games: The impact of effort on contributions. Journal of Neuroscience, Psychology and Economics, 2(1), 59-67. doi:10.i(].17/fl(MIIM5H

Nishi, A., Shirado, H., Rand, D. G., \& Christakis, N. A. (2015). Inequality and visibility of wealth in experimental social networks. Nature, 526(7573), 426-429. doi:10.1038/nature15392

Osman, M. (2014). Future-minded: The psychology of agency and control. London: Palgrave Macmillan.

Parks, C. D., Joireman, J., \& Van Lange, P. A. M. (2013). Cooperation, trust, and antagonism how public goods are promoted. Psychological Science in the Public Interest, 14(3), 119-165. doi:10.1177/1529100612474436

Penner, L. A., Dovidio, J. F., Piliavin, J. A., \& Schroeder, D. A. (2005). Prosocial behavior: Multilevel perspectives. Annual Review of Psychology, 56, 365-392. doi:10.1146/annurev.psych.56.091103.070141 
Piff, P. K., Kraus, M. W., Côté, S., Cheng, B. H., \& Keltner, D. (2010). Having less, giving more: The influence of social class on prosocial behavior. Journal of Personality and Social Psychology, 99(5), 771-784. doi:10.1037/a0020092

Pruitt, D. G., \& Kimmel, M. J. (1977). Twenty years of experimental gaming: Critique, synthesis, and suggestions for the future. Annual Review of Psychology, 28(1), 363-392. doi:10.1146/annurev.ps.28.020177.002051

Reinstein, D., \& Riener, G. (2009). House money effects on charitable giving: An experiment. Paper presented at the Working Paper, University of Essex.

Rockmann, K. W., \& Northcraft, G. B. (2008). To be or not to be trusted: The influence of media richness on defection and deception. Organzation Behavior and Human Decision Process, 107(2), 106-122. doi:10.1016/j.obhdp.2008.02.002

Rumble, A. C., Van Lange, P. A. M., \& Parks, C. D. (2010). The benefits of empathy: When empathy may sustain cooperation in social dilemmas. European Journal of Social Psychology, 40(5), 856-866. doi:10.1002/ejsp.659

Segal, U., \& Sobel, J. (2007). Tit for tat: Foundations of preferences for reciprocity in strategic settings. Journal of Economic Theory, 136(1), 197-216.

Stellar, J. E., Manzo, V. M., Kraus, M. W., \& Keltner, D. (2012). Class and compassion: Socioeconomic factors predict responses to suffering. Emotion, 12(3), 449-459. doi:10.1037/a0026508

Stephan, W. G., \& Finlay, K. (1999). The role of empathy in improving intergroup relations. Journal of Social Issues, 55(4), 729-743. doi:10.1111/0022-4537.00144

Tyler, T. R., \& Blader, S. L. (2003). The group engagement model: Procedural justice, social identity, and cooperative behavior. Personality and Social Psychology Review, 7(4), 349-361. doi:10.1207/s15327957pspr0704_07

Van Lange, P. A. M. (2008). Does empathy trigger only altruistic motivation? How about selflessness or justice? Emotion, 8(6), 766-774. doi:10.1037/a0013967

Van Lange, P. A. M., Balliet, D., Parks, C. D., \& Van Vugt, M. (2013). Social dilemmas: Understanding human cooperation. New York: Oxford University Press. 
Van Lange, P. A. M., \& Gallucci, M. (2003). Bridging psychology and game theory yields interdependence theory. Behavioral and Brain Sciences, 26(2), 177.

Weber, J. M., Kopelman, S., \& Messick, D. M. (2004). A conceptual review of decision making in social dilemmas: Applying a logic of appropriateness. Personality and Social Psychology Review, 8(3), 281-307. doi:10.1207/s15327957pspr0803_4

Willer, R. (2009a). Groups reward individual sacrifice: The status solution to the collective action problem. American Sociological Review, 74(1), 23-43. doi:10.1177/000312240907400102

Willer, R. (2009b). A status theory of collective action. In S. R. Thye \& E. Lawler (Eds.), Altruism and Prosocial Behavior in Group (Vol. 26, pp. 133-163): Emerald Group Publishing Limited. doi:10.1108/s0882-6145(2009)0000026009

Xu, H., Kou, Y., \& Zhong, N. (2012). The effect of empathy on cooperation, forgiveness, and "Returning Good for Evil" in the prisoner's dilemma. Public Personnel Management, 41(5), 105-115. doi:10.1177/009102601204100510

Yamagishi, T., Mifune, N., Liu, J. H., \& Pauling, J. (2008). Exchanges of group-based favours: Ingroup bias in the prisoner's dilemma game with minimal groups in Japan and New Zealand. Asian Journal of Social Psychology, 11(3), 196-207. doi:10.1111/j.1467-839X.2008.00258.x

Yamagishi, T., \& Yamagishi, M. (1994). Trust and commitment in the United States and Japan. Motivation and Emotion, 18(2), 129-166. doi:10.1007/bf02249397

Yamamoto, S., \& Takimoto, A. (2012). Empathy and fairness: Psychological mechanisms for eliciting and maintaining prosociality and cooperation in primates. Social Justice Research, 25(3), $233-255$. 
Figure 1. Mean of PoC by round and by condition for Experiment 1 (Standard Error $1+$ )

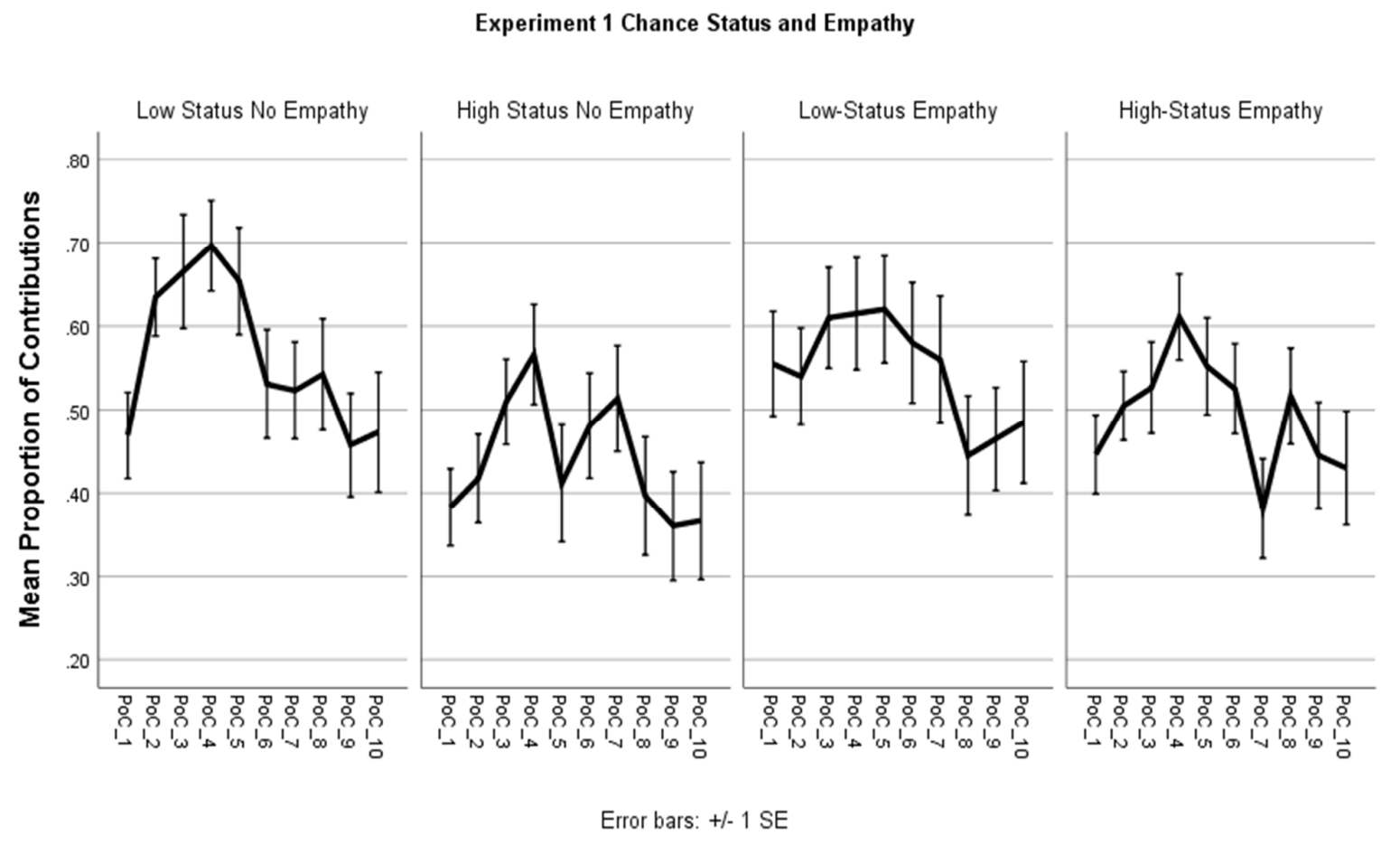


Figure. $2 A$. Mean of PoC by round and by condition for Experiment 2 (Standard Error $1+/$ )

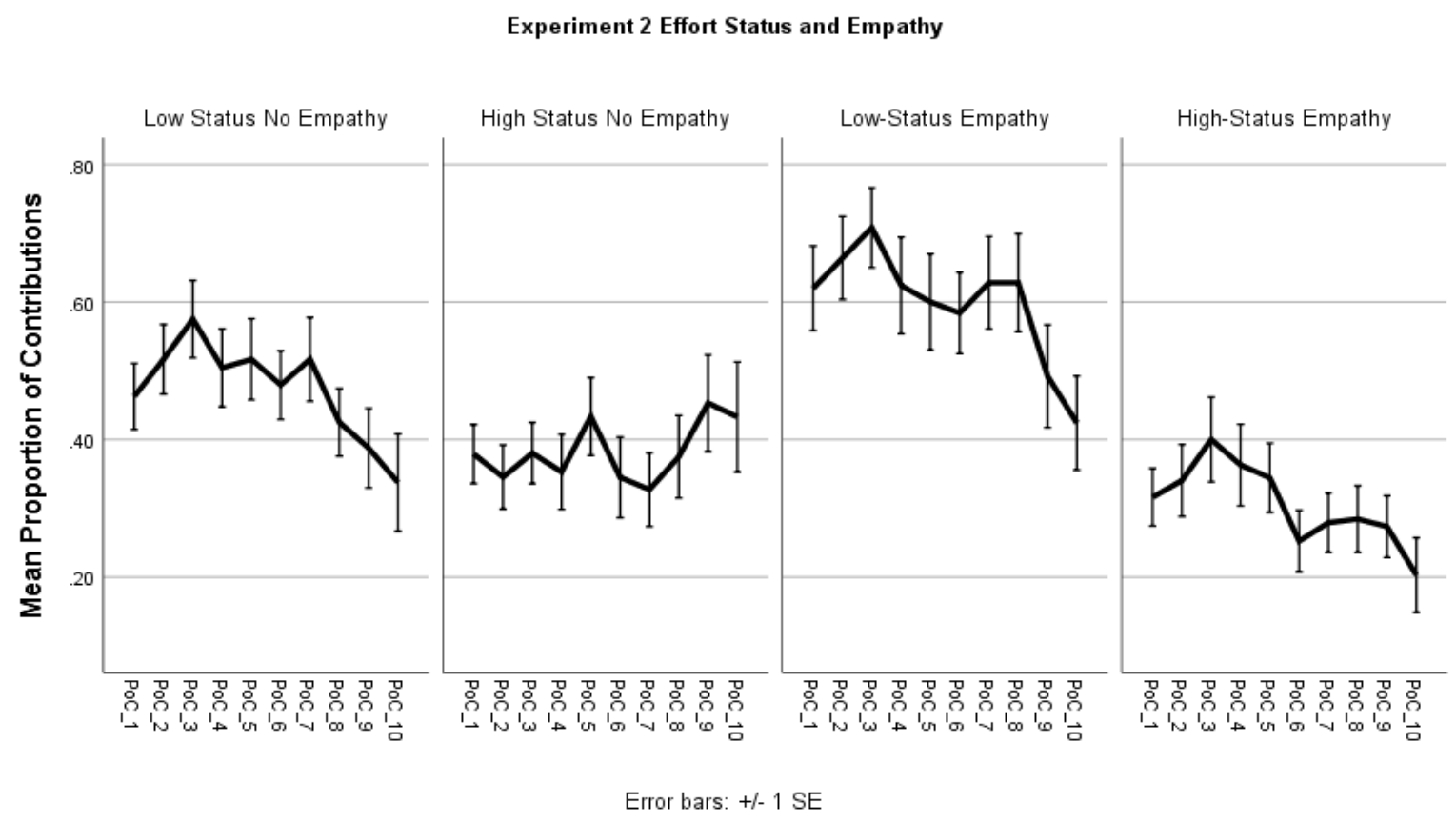


Figure. 3 Mean of PoC by round and by condition for Experiment 3 (Standard Error $1+$ )

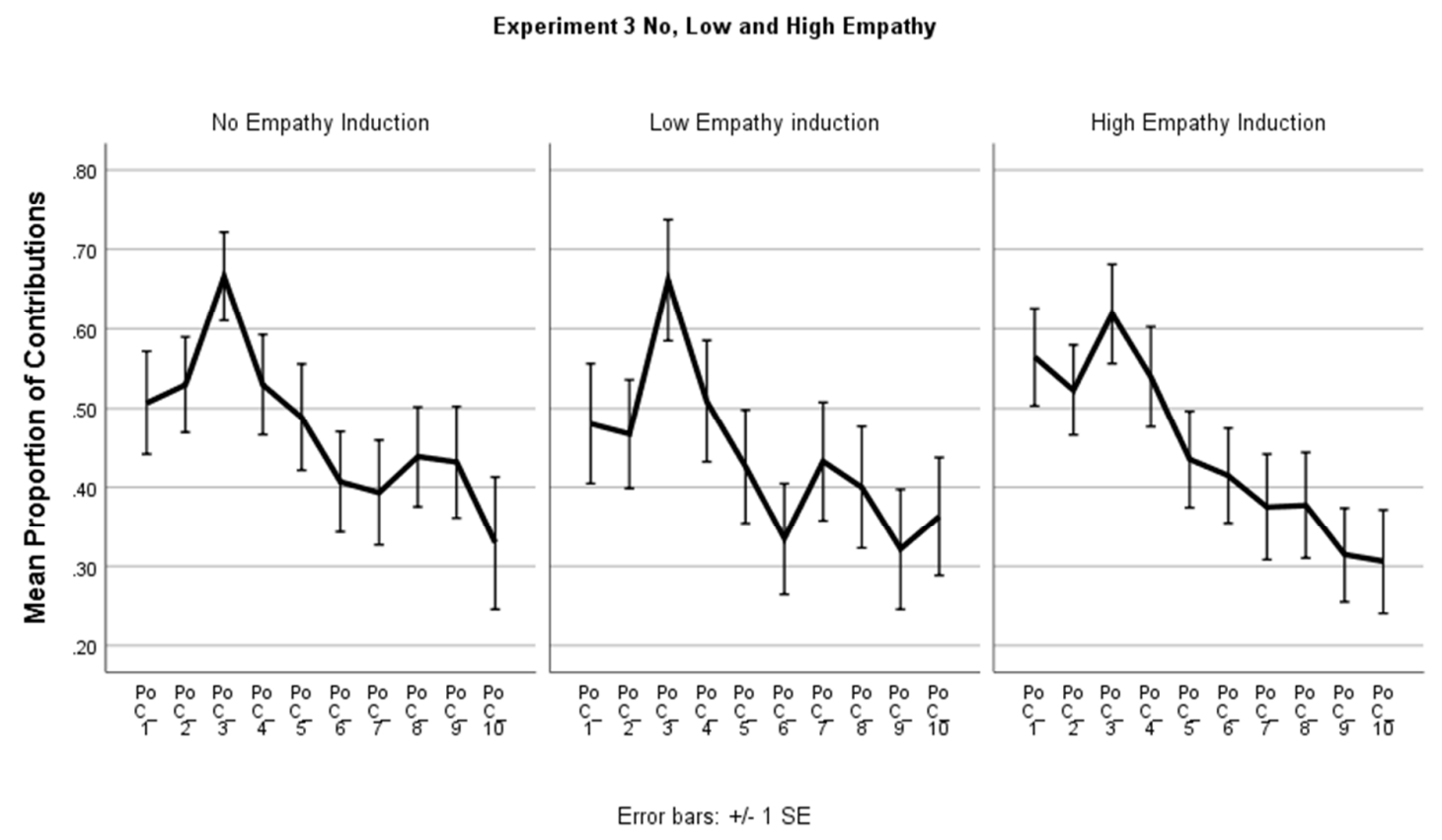


Figure 4. Mean of PoC by round and by condition for Experiment 4 (Standard Error $1+$ )

Experiment 4 Chance Status and Empathy in a 2-player PGG

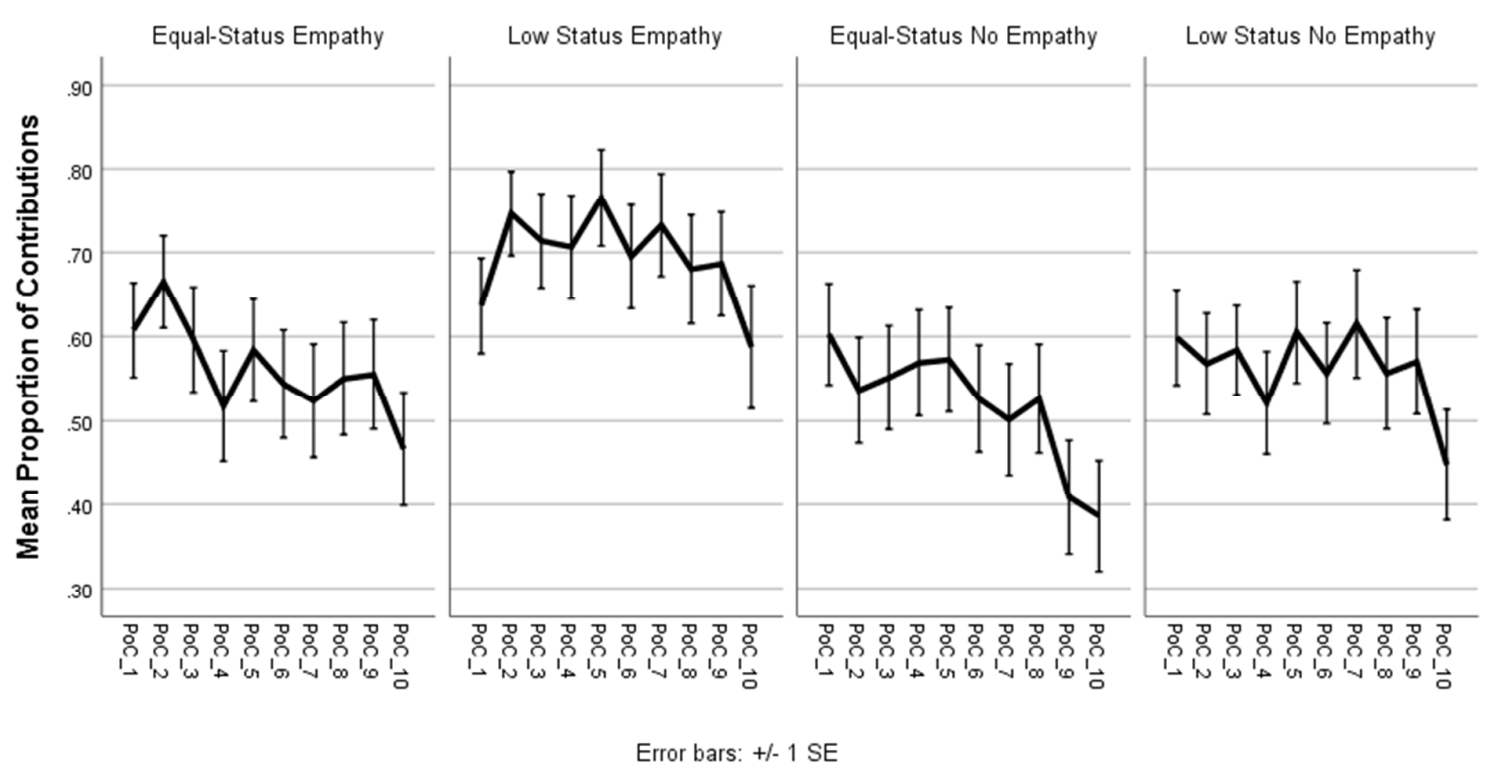

